Article

\title{
Numerical Modeling of Sublimation of Ammonium Carbamate Applied to Supply System of NOx Reductant
}

\author{
Sang-Hee Woo ${ }^{1}\left(\right.$, Jung-Hun Noh ${ }^{2}\left(\mathbb{D}\right.$, Hassan Raza ${ }^{1,3}$ and Hongsuk Kim ${ }^{1, * \mathbb{C}}$ \\ 1 Environment System Research Division, Korea Institute of Machinery and Materials, 156 Gajeong-ro, \\ Yuseong-gu, Daejeon 34103, Korea; wsh@kimm.re.kr (S.-H.W.); hassan@kimm.re.kr (H.R.) \\ $2 \mathrm{AI}$ and Mechanical System Center, Institute for Advanced Engineering, 175-28, Goan-ro 51beon-gil, \\ Baegam-myeon, Cheoin-gu, Yongin-si, Yongin 17180, Korea; junghunnoh@iae.re.kr \\ 3 Department of Environment \& Energy Mechanical Engineering, University of Science and Technology, \\ 217 Gajeong-ro, Yuseong-gu, Daejeon 34113, Korea \\ * Correspondence: hongsuk@kimm.re.kr; Tel.: +82-42-868-7367
}

Citation: Woo, S.-H.; Noh, J.-H.;

Raza, H.; Kim, H. Numerical

Modeling of Sublimation of Ammonium Carbamate Applied to Supply System of NOx Reductant. Energies 2021, 14, 3795. https:// doi.org/10.3390/en14133795

Academic Editor: Mejdi Jeguirim

Received: 17 May 2021

Accepted: 21 June 2021

Published: 24 June 2021

Publisher's Note: MDPI stays neutral with regard to jurisdictional claims in published maps and institutional affiliations.

Copyright: (c) 2021 by the authors. Licensee MDPI, Basel, Switzerland. This article is an open access article distributed under the terms and conditions of the Creative Commons Attribution (CC BY) license (https:// creativecommons.org/licenses/by/ $4.0 /)$.

\begin{abstract}
Recently, ammonium carbamate (AC) has attracted attention as a substitute for urea, which is a commonly used reductant for $\mathrm{NO}_{\mathrm{x}}$ emitted from combustion engines. The AC exists as a solid at room temperature, and it is decomposed to $\mathrm{NH}_{3}$ and $\mathrm{CO}_{2}$ gases by heating. Therefore, adequate heat transfer is an essential issue in the design of AC pyrolysis reactor. In this study, a numerical model that describes the sublimation of AC was developed. For modeling, this study considered the three different calculation zones: solid-phase zone, gas-phase zone, and sublimation zone. Additionally, during the sublimation process, collapse of upper solid AC into the hollow space below by the effect of gravity is considered. As a result, it is presented that the modeling shows reasonable information about the AC sublimation in a reactor, such as temperatures in a reactor, pressure of reactor, and flow rate of sublimated gas. However, it is also found that accurate prediction of spatial temperature distribution is challenging because it is related to the accurate prediction of the internal shape of AC and its collapse in a reactor.
\end{abstract}

Keywords: ammonium carbamate; sublimation; numerical method; ammonia; NOx

\section{Introduction}

As one of the major sources of air pollutants, $\mathrm{NO}_{\mathrm{x}}$ emissions have been strictly regulated. [1]. However, approximately 500 million tons of $\mathrm{NO}_{\mathrm{x}}$ are still emitted annually from vehicles worldwide [2], affecting the quality of human life. Selective catalytic reduction (SCR) has been the most commonly used technology to reduce $\mathrm{NO}_{x}$ emissions from vehicles [3,4]. The SCR refers to a catalyst system that converts $\mathrm{NO}$ or $\mathrm{NO}_{2}$ into $\mathrm{N}_{2}$ and $\mathrm{H}_{2} \mathrm{O}$ by reacting with $\mathrm{NH}_{3}$, and it shows an exceptionally high $\mathrm{NO}_{x}$ reduction efficiency and high system reliability. However, $\mathrm{NH}_{3}$ is needed as a $\mathrm{NO}_{\mathbf{x}}$ reducing agent in the SCR. It is a toxic substance and very dangerous in the event of a leak. Additionally, it is difficult to store in a liquid or gaseous state. Therefore, many vehicles currently use urea $\left(\mathrm{CO}\left(\mathrm{NH}_{2}\right)_{2}\right)$ water solution to supply $\mathrm{NH}_{3}$. The urea water solution is decomposed into $\mathrm{NH}_{3}$ and $\mathrm{CO}_{2}$ when it is sprayed onto high-temperature exhaust gases. However, effective decomposition of urea solution usually requires a high exhaust gas temperature of $200^{\circ} \mathrm{C}$ or more [5]. Due to this requirement, a substantial amount of $\mathrm{NO}_{\mathrm{x}}$ is emitted during low temperature operating conditions [6]. One of the other disadvantages is that the urea solution can freeze below $-12{ }^{\circ} \mathrm{C}$ [7]. Additionally, it is not easy to keep the uniform distribution of ammonia in a catalyst during transient engine operating conditions [8].

The AC (ammonium carbamate, $\mathrm{H}_{2} \mathrm{NCOONH}_{4}$ ) has been proposed as an alternative of urea [5]. The $\mathrm{AC}$ can be sublimated from solid to gas mixture of $\mathrm{NH}_{3}$ and $\mathrm{CO}_{2}$ at temperatures (approximately $60^{\circ} \mathrm{C}$ at $1 \mathrm{~atm}$ ) lower than those for urea. Another advantage of $\mathrm{AC}$ is that the storage capacity of $\mathrm{NH}_{3}$ is about three times larger than that of urea 
solution. Besides, the $\mathrm{NH}_{3}$ gas produced from $\mathrm{AC}$ has better mixing characteristics with exhaust gas than that of urea solution. In general, AC is stored in a reactor. The reactor's pressure increases when it is heated because some amount of AC is sublimated in the reactor. Then, the $\mathrm{NH}_{3}$ gas is injected into the exhaust gas using the elevated pressure [5]. However, it is difficult to control the sublimation rate of AC because of spatially uneven distribution of $\mathrm{AC}$ mass and temperature in the reactor. For example, the AC contacting with the heat sources is sublimated at first, and a gas space is created there. After that, the AC that exists spatially apart from the heat sources is sublimated by the effect of convective heat transfer. Such a temporally and spatially complex sublimation process results in a non-uniform sublimation rate. Therefore, optimal design of the reactor is necessary to control the sublimation rate effectively. Previous researchers have investigated the simple design parameters of AC reactor only by experimental methods [9-11]. However, it was not easy to clearly understand the heat and mass transfer phenomena in the reactor. Such difficulties hinder the optimal design of the reactor.

Many numerical models have been developed to solve engineering problems of phase change from solid to liquid [12-14] or liquid to gas $[15,16]$. However, numerical models for phase change from solid to gas have not been proposed well, because it is not a common phenomenon encountered in engineering problems. Kim et al. [17] developed a numerical method to investigate the frosting of water. They tried to predict the variation of heat transfer coefficient owing to the frost. They also simulated the growth of frost by the deposition of $\mathrm{H}_{2} \mathrm{O}$ molecules in the air on a cold surface. Zhang et al. [18] calculated the amount of heat energy removed by sublimation, evaporation, and freezing that occurred on a porous plate, which was soaked in the water. However, the porous plate's shape did not vary, and only the heat and mass transfer were analyzed. Zadravec et al. [19] investigated the variation of the interface height by simulating the material's freeze-drying process in a vial. However, this study considered only the height of the interface. It was not developed to interpret the three-dimensional sublimation phenomenon. As seen above, there have been many simulation studies on the phase change from gases to solid or solid to gases. However, as far as we know, there are no three-dimensional simulation studies about AC sublimation. This seems to be because AC is the newly introduced material for ammonia storage.

This study's objective is to develop a numerical model, which simulates the sublimation of $\mathrm{AC}$ for use in the optimal design of a reactor.

\section{Materials and Methods}

\subsection{Experiment Set-Up}

Experiments on AC sublimation were conducted to verify the numerical model developed in this study. As shown in Figure 1, the experimental apparatus is divided into three parts: AC reactor (pyrolysis space), heated water supply device, and heated air supply device. The water heated at $90^{\circ} \mathrm{C}$ is circulated outside the reactor to supply heat. Two glass plates are installed on the top ceiling of the reactor to visualize the shape of solid-phase AC. The hot air heated to $120{ }^{\circ} \mathrm{C}$ is supplied between the two glass plates to prevent the re-solidification of $\mathrm{NH}_{3}$ and $\mathrm{CO}_{2}$ gases on the surface of the glass plate. In the $\mathrm{AC}$ reactor, four fins are installed to enhance heat transfer characteristics. Five thermocouple rods (TRF1, TRF2, TRF3, TRA1, TRA2) are installed in the reactor to measure temperature distribution. TRF1, TRF2, and TRF3 are installed near a fin that are expected to sublimate first. TRA1 and TRA2 are installed in the middle between two fins that are expected to sublimate later. In each of the rods, four thermocouples are implanted at regular intervals. The entire experimental apparatus is covered with insulation material.

The AC exists in the form of powder. However, when it is exposed at a certain condition for a long time, the AC may harden and agglomerate. In this study, the AC was crushed into small powders before the tests.

$\mathrm{NH}_{3}$ and $\mathrm{CO}_{2}$ gas mixtures were exhausted from the bottom of the vessel. The pressure was measured using a pressure sensor ( $\mathrm{PSH}$, Sensys, Korea) at the outlet. In the 
experiment, after $30 \mathrm{~min}$ of warm water circulation, the outlet valve was opened, and the flow rate of gas was measured by MFC (mass flow controller). The outlet gas line was heated to $120^{\circ} \mathrm{C}$ to prevent clogging, owing to the re-solidification of $\mathrm{NH}_{3}$ and $\mathrm{CO}_{2}$ gases.
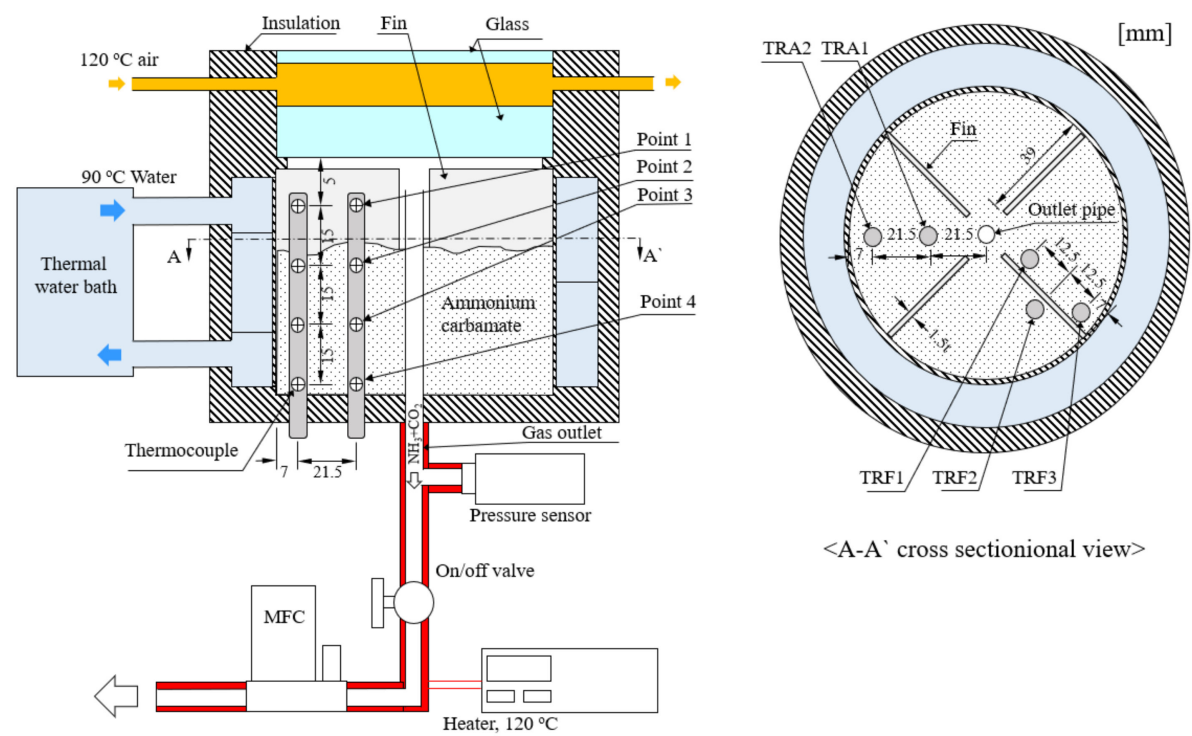

Figure 1. Schematic of experimental set-up for validation of AC sublimation model.

\subsection{Numerical Method}

\subsubsection{Sublimation Numerical Analysis Model}

Three kinds of calculation zones are considered in the numerical model developed in this study: solid-phase zone, gas-phase zone, and sublimation zone. Only solid AC is present in the solid-phase zone. The gas-phase zone also only contains gases. The sublimation zone is a region where the temperature reaches the critical temperature for sublimation. Both solid and gas exist in the sublimation zone.

The temperature of every zone is monitored at each iteration of the calculation to classify the zone. When the zone's temperature is higher than the sublimation critical temperature $\left(T_{t h}\right)$, the solid zone transforms into a sublimation zone. Here, the $T_{t h}$ is determined by the Figure 2, which is obtained from an experiment of reference [9]. The solid-phase and gas-phase mass ratio in the zones $\left(\rho_{s}\right)$ is calculated at each iteration of calculation to classify the zone. When one mole of solid AC is pyrolyzed, one mole of $\mathrm{CO}_{2}$ and two moles of $\mathrm{NH}_{3}$ gas are generated. Generated $\mathrm{CO}_{2}$ and $\mathrm{NH}_{3}$ gas are considered by source term of fluid in the sublimation zone. If $\rho_{S}$ is decreased to zero, the sublimation zone transforms to a gas-phase zone. In the gas-phase zone, conservation equations of computational fluid dynamics (CFD) are applied to calculate the conserved variables.

Figure 3 shows the concept of a model that explains how to simulate the change in shape of a solid AC where sublimation occurred. Figure 3 is expressed two-dimensionally for ease of understanding, but the real model was calculated three-dimensionally. Step 1 is the initial step at Time $i$. The distinction between the solid-phase and gas-phase zones is evident, and there is no sublimation zone. Step 2 is the heating stage. The solid-phase zone is transformed to the sublimation zone when the cell temperature $\left(T_{S}\right)$ is greater than the sublimation critical temperature $\left(T_{t h}\right)$. The mass ratio of solid-phase and gas-phase $\left(\rho_{s}\right)$ is also calculated in Step 2. In Step 3, the sublimation zone's cell transforming to the gas-phase zone is determined based on the $\rho_{s}$. In Step 4 , the solid phase zone is shifted in the direction of gravity to fill the voids created by the phase transformation. It was assumed that solid AC was in powder form, as it had weak bonding forces, and it shifted in the direction of gravity without plastic action. Steps 1-4 are repeated until the residue converges below a specific value. Furthermore, the time step is shifted forward from $i$ to $i+1$. For the next time step, the zone information (solid, gas, sublimation) calculated in the 
previous iteration is used as the initial value. In this study, the amount of sublimated AC, the pressure of the pyrolysis vessel, and the amount of $\mathrm{NH}_{3}$ gas generated are predicted by continuing this calculation procedure.

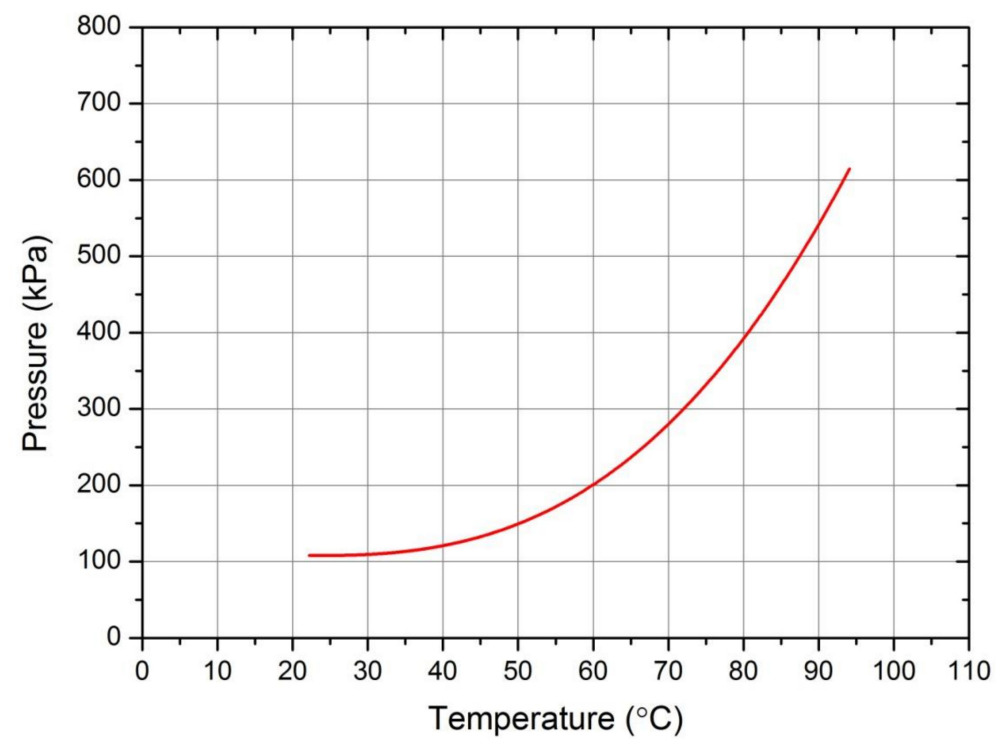

Figure 2. Equilibrium pressure of AC with respect to the temperature measured in a closed chamber [9]. Reprinted with permission from ref. [9]. Copyright 2021 Elsevier.

Step 1: Initial state $(i)$

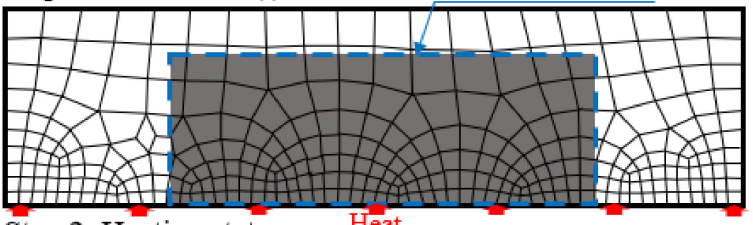

Step 2: Heating state

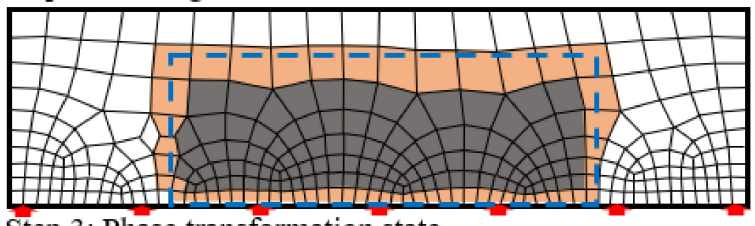

Step 3: Phase transformation state

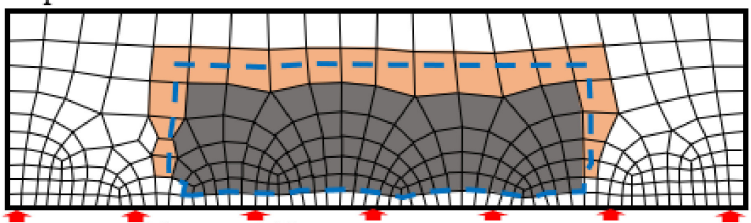

Step 4: Solid zone shift

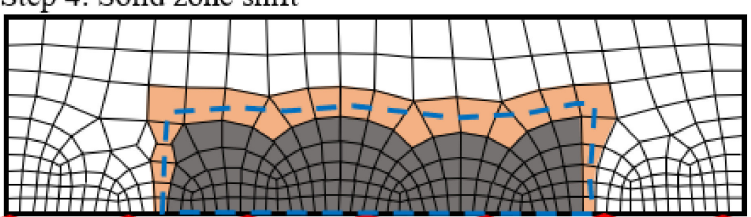

Step 4: Advanced time (i+1)

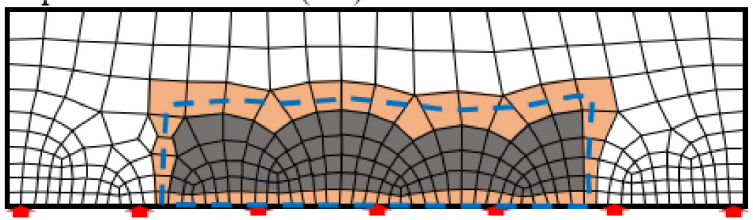

\begin{tabular}{cc}
\hline Zone & Number of grid \\
\hline Solid phase & 212 \\
\hline Sublimation & 0 \\
\hline$\square$ Gas phase & 118 \\
\hline
\end{tabular}

\begin{tabular}{cc}
\hline Zone & Number of grid \\
\hline Solid phase & 156 \\
\hline Sublimation & 56 \\
\hline Gas phase & 118 \\
\hline
\end{tabular}

\begin{tabular}{cc}
\hline Zone & Number of grid \\
\hline Solid phase & 156 \\
\hline Sublimation & 20 \\
\hline Gas phase & 154 \\
\hline
\end{tabular}

\begin{tabular}{cc}
\hline & \\
\hline Zone & Number of grid \\
\hline Solid phase & 156 \\
\hline Sublimation & 20 \\
\hline Gas phase & 154 \\
\hline & \\
\hline Zone & Number of grid \\
\hline Solid phase & 120 \\
\hline Sublimation & $56+36$ \\
\hline Gas phase & 154 \\
\hline
\end{tabular}

Figure 3. Concept of the model: Changes in the shape and location of solid AC where sublimation occurs due to heat transfer. 
A commercial CFD program ANSYS FLUENT 19.2, was used in this study. The general mass, momentum, and energy conservation equations of the commercial program were used. As a turbulent model, the standard $k-\varepsilon$ model was used. The latent heat of sublimation of $\mathrm{AC}, S_{e}$, was added to the energy equation as follows:

$$
\frac{\partial\left(\rho c_{p} T\right)}{\partial t}+\nabla \cdot\left(\rho c_{p} T\right)=-\nabla(k \nabla T)+S_{e},
$$

where $\rho$ is the density, $c_{p}$ is the specific heat, $T$ is the temperature, $k$ is the thermal conductivity. The generation of $\mathrm{NH}_{3}$ and $\mathrm{CO}_{2}$ gases by $\mathrm{AC}$ sublimation is incorporated in the species transport equation as follows:

$$
\frac{\partial\left(c_{k}\right)}{\partial t}+\nabla \cdot\left(c_{k} u\right)=-\nabla\left(D_{k} \nabla c_{k}\right)+S_{k}
$$

where $c_{k}$ is the concentration of each species, $u$ is the velocity, $D_{k}$ is the diffusion coefficient of each species, and $S_{k}$ is the source term for each species generation. The $\mathrm{NH}_{3}$ and $\mathrm{CO}_{2}$ gases generated by AC sublimation are calculated in terms of $S_{k}$.

Properties of gases and solid material of reactor are listed in Table 1 which are mainly citing NIST (National Institute of Standard and Technology) data. The sublimation heat of solid AC is $159.94 \mathrm{~kJ} / \mathrm{mol}$ [20].

Table 1. Physical properties of working fluid and solid.

\begin{tabular}{cccccc}
\hline & Description & Density $\left[\mathbf{k g} / \mathbf{m}^{\mathbf{3}}\right]$ & Viscosity [Pa-s] & $\begin{array}{c}\text { Specific Heat } \\
\text { [J/kg-K] }\end{array}$ & $\begin{array}{c}\text { Thermal Conductivity } \\
\text { [W/m-K] }\end{array}$ \\
\hline \multirow{4}{*}{ Fluid } & Air & 0.898 & $2.264 \times 10^{-5}$ & 1011 & 0.032 \\
& Ammonia & 0.689 & $1.015 \times 10^{-5}$ & 2158 & 0.025 \\
& Carbon Dioxide & 0.730 & $1.801 \times 10^{-5}$ & 908 & 0.022 \\
Water & 965.3 & $0.315 \times 10^{-3}$ & 4206 & 0.675 \\
\multirow{3}{*}{ Solid } & SUS 304 & 7930 & - & 502 & 16.2 \\
& Insulator (Urethane) & 70 & - & 1045 & 0.026 \\
& Ammonia Carbamate & 1380 & - & 1670 & 2.0 \\
& Glass & 2800 & - & 750 & 0.7 \\
\hline
\end{tabular}

Commercially available ANSYS Fluent 19.2 software (Canonsburg, Pennsylvania US) was used. Sublimation of solid AC was calculated by a user-defined function. The calculating elements numbered from 1.1 million to 1.7 million were tested for grid independence, and the number of elements was decided to about 1.3 million. The coupled governing equations were discretized using the finite volume method and solved with SIMPLE algorithm. For actual analysis, convergence conditions of solution were taken to be less than $10^{-5}$ of relative uncertainty level.

\subsubsection{Model Validation}

The sublimation model developed in this study was verified by comparing it with experimental results. As shown in Figure 4, the calculating area is identical to the pyrolysis space inside the AC reactor. The inlet boundary conditions of air supplied to the space between the two glass plates are as follows: the temperature is $120^{\circ} \mathrm{C}$, and the velocity of flow is $1 \mathrm{~m} / \mathrm{s}$, respectively. The inlet boundary conditions of warm water for supplying heat are a temperature of $90{ }^{\circ} \mathrm{C}$ and a flow rate of $5 \mathrm{~L} / \mathrm{min}$. All the outlet boundary conditions, such as the heating air, vessel's outlet, and the warm water outlet, are set as the pressure outlet. All the boundary conditions of the outside wall (except the top of the glass) are set as adiabatic conditions. The glass plates at the top of the experimental apparatus are exposed to ambient air. Therefore, a general convection heat transfer condition is applied to the glass plate surface. The glass plate surface's heat transfer coefficient is $6 \mathrm{~W} / \mathrm{m}^{2}{ }^{\circ} \mathrm{C}$, and the ambient air temperature is set to $25^{\circ} \mathrm{C}$. All the wall boundary layers exposed to 
fluid are in the no-slip condition. The pyrolysis vessel's initial temperature is $37^{\circ} \mathrm{C}$, which was the air temperature of the experimental pyrolysis vessel when that of the warm water attained $90^{\circ} \mathrm{C}$. The model is calculated transiently. Air, $\mathrm{NH}_{3}$, and $\mathrm{CO}_{2}$ are assumed to be ideal gases. The time step of the calculation is $1 \mathrm{~min}$, and the calculation results are summarized every $10 \mathrm{~min}$.

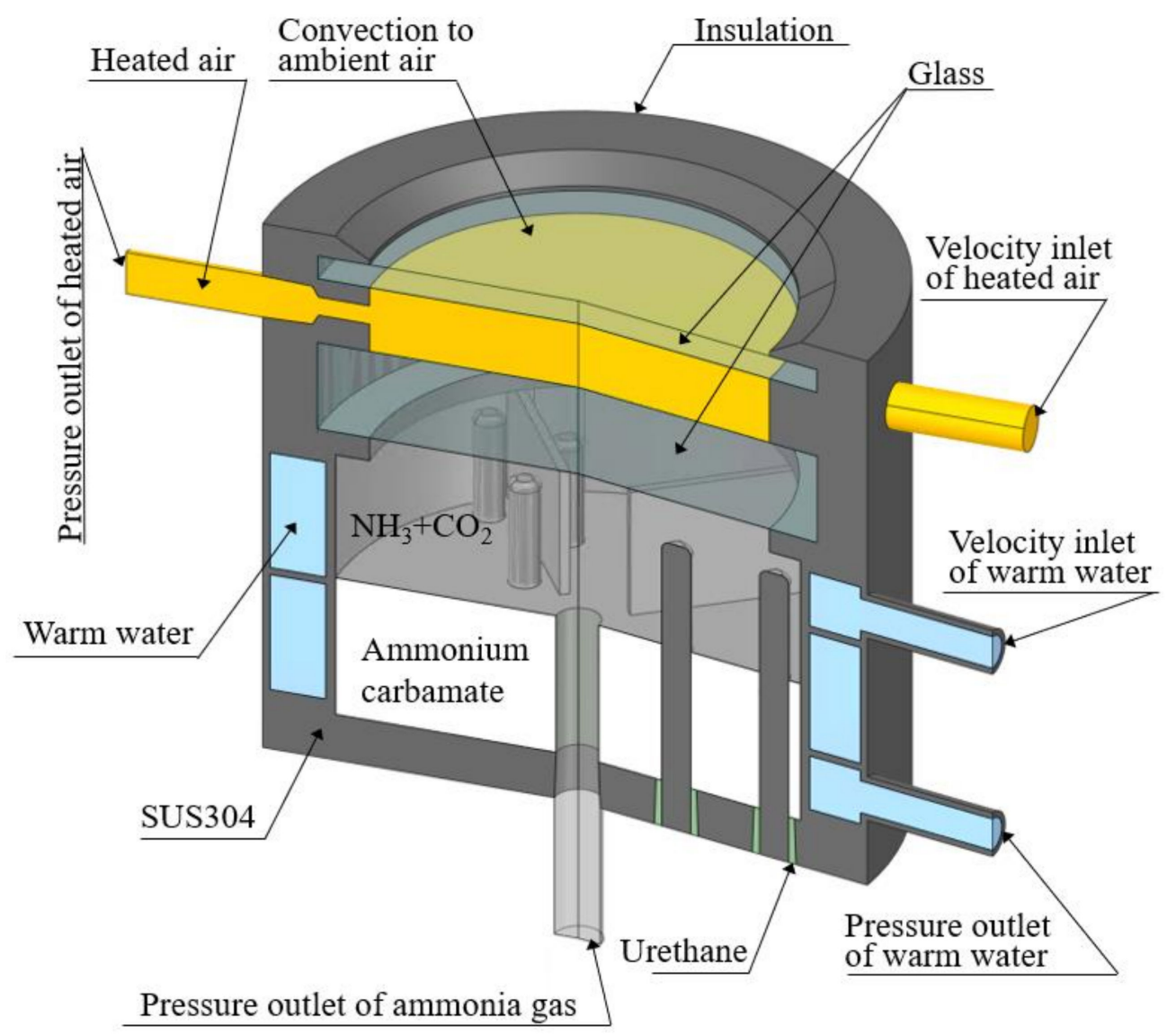

Figure 4. Schematic diagram and boundary definitions of AC sublimation model validation.

\section{Results and Discussion}

The variations of the shape of $\mathrm{AC}$ in the experiment and simulation are compared in Figure 5. In the experiment, the solid AC area decreases gradually owing to sublimation after heat is supplied. In particular, the solid regions adjacent to the fins and side wall (where heat is supplied directly) are reduced substantially. It means that the fin's large contact area with AC enhances the sublimation. Hence, it can be mentioned that the increasing the number of fins is an effective way to ensure a consistent pyrolysis performance when designing an $\mathrm{AC}$ reactor. The simulation also show similar results of the rapid sublimation of solid AC around the sidewall and the fins.

The reactor pressures and the gas flow rates of experiment and simulation are compared in Figure 6. In the experiment, the reactor pressure increases to 0.1 bar at $30 \mathrm{~min}$ because the exhaust line is closed. After the exhaust valve is opened, it decreases to $0.03-0.04$ bar. The flow rate of the exhaust from the reactor decreased from $0.271 / \mathrm{min}$ at $30 \mathrm{~min}$ to $0.05 \mathrm{l} / \mathrm{min}$ at $150 \mathrm{~min}$ in the experiment. The simulation result of pressures and flow rate show similar changes with experiments. From the Figure 6, it can be said that the developed sublimation model well predicted reactor pressure and the ammonia gas flow rate. 

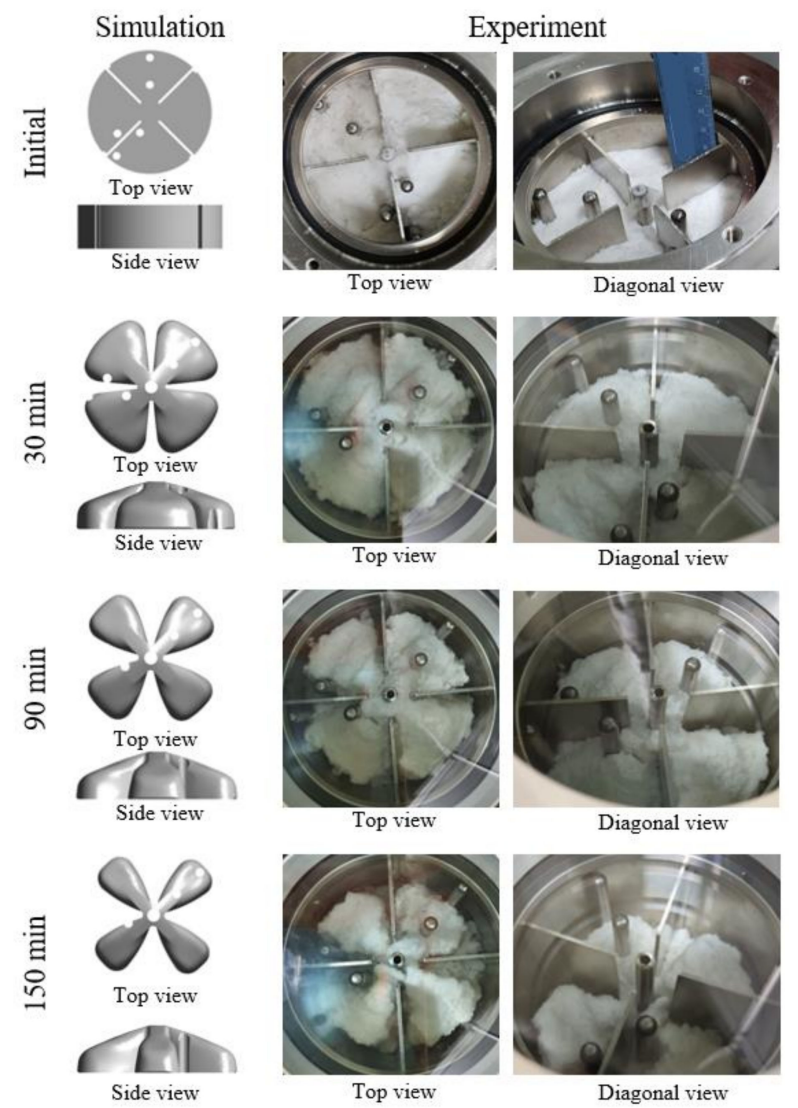

Figure 5. Variation of the shape of solid ammonium carbamate when the reactor is heated.

(a)

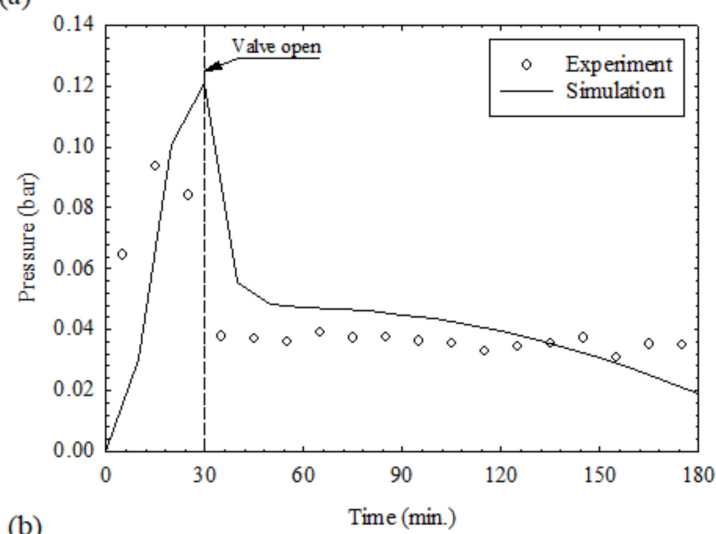

(b)

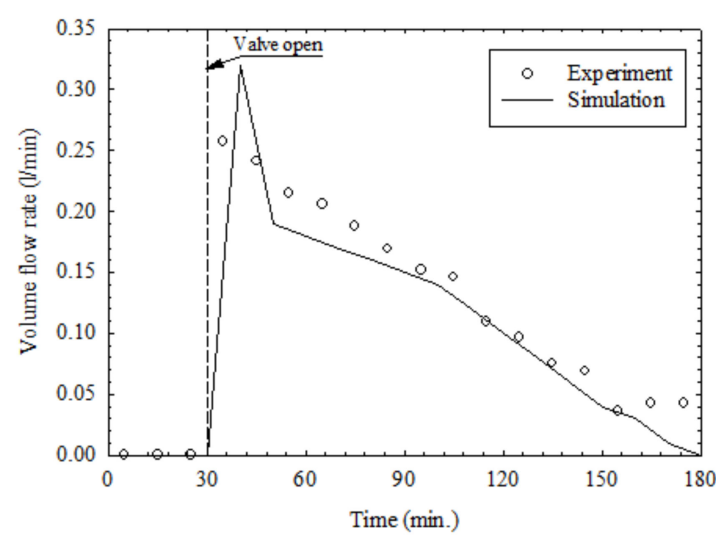

Figure 6. Pyrolysis reactor (a) pressure and (b) exhaust gas flow rate variation. 
The averaged pyrolysis rate was calculated using the above simulation results with 30-min intervals, and is shown in Figure 7 . The averaged pyrolysis rate during the first $30 \mathrm{~min}$ is $4.32 \mathrm{~g} / \mathrm{min}$, and it decreases rapidly to $0.2 \mathrm{~g} / \mathrm{min}$. This is because the AC adjacent to the sidewall or fins are sublimated rapidly by conductive heat transfer in the early stage of the experiment. After that, the sublimation rate of the remaining AC is controlled by the heat supplied by convection.

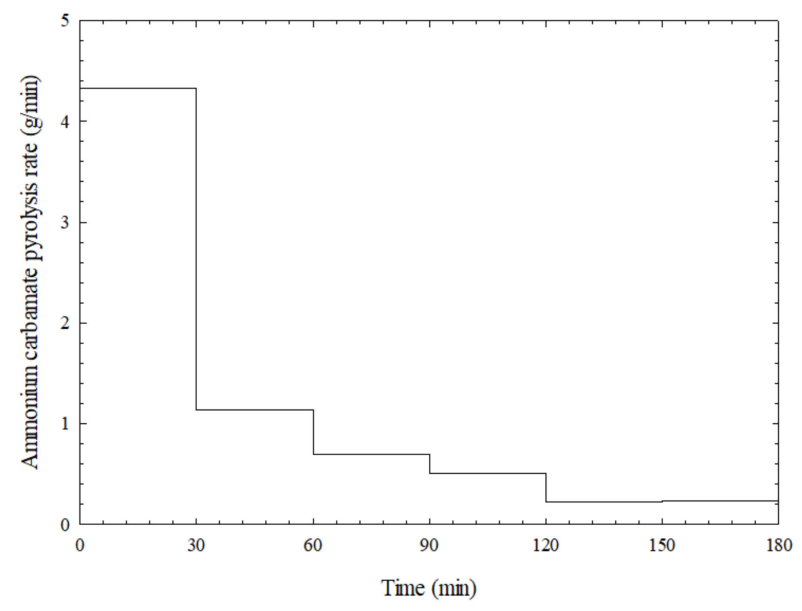

Figure 7. Ammonium carbamate pyrolysis rate variation.

The simulated temperatures are compared with the experimental results in Figure 8. All the temperatures of thermocouples increase linearly by heating initially, and the temperatures are saturated after sublimation has occurred. This means that all energies supplied to the reactor are used as the latent heat of sublimation. The simulation also shows the saturation of temperatures. However, in the experiment, the temperatures are saturated quickly, whereas it takes longer for saturation in the simulation. It seems that this difference comes from the uncertainties of simulation, such as the inexact values of heat capacity or density of solid AC the heat transfer characteristics of porous space in the solid AC may also be affected.

Comparing the temperature distribution of the experiment reveals that TRF3 and TRA2 are the hottest $\left(70-80^{\circ} \mathrm{C}\right)$. It seems that the thermocouples in these regions were rapidly exposed to hot gases because of fast sublimation by a large amount of heat supplied from the sidewall. The temperatures of TRF1 and TRF2 are the second highest $\left(65-72{ }^{\circ} \mathrm{C}\right)$ because these were close to the fin and exposed to the gases after about $90 \mathrm{~min}$. The temperature of TRA1 are the lowest $\left(62-70^{\circ} \mathrm{C}\right)$ because it was farthest from the fin and sidewall. It seems that the thermocouple rod of TRA1 was buried in AC for the entire experiment. Similarly, in the simulation, the temperatures of TRF3 and TRA2 are the highest, and that of TRA1 is the lowest. These are similar with the experiment results.

Generally, the temperature measured in the experiment is high in the order of height. The temperatures are low in the AC or near the AC because the AC absorbs heat during sublimation. However, there is an exceptional temperature distribution in the experiment. For example, the temperature at Point 4 of TRA1 is higher than that at Points 2 and 3 of TRA1 during the entire experiment. Additionally, the temperatures at Point 4 of each TRF1, TRF2, and TRA2 are higher than that at Points 2 and 3 of each TRF1, TRF2, and TRA2 during the first 100 min of the experiment. It seems that the voids in the AC cause an unexpected temperature distribution. The thermocouple exposed to the gases in a void shows a higher temperature than that of the thermocouple buried in AC because of little or no latent heat of AC sublimation. After $100 \mathrm{~min}$, all temperatures of Point 4 were lower than point 2 and point 3. This means that the AC near Point 4 collapsed, and the thermocouples at Point 4 were buried in AC again. 
(a)

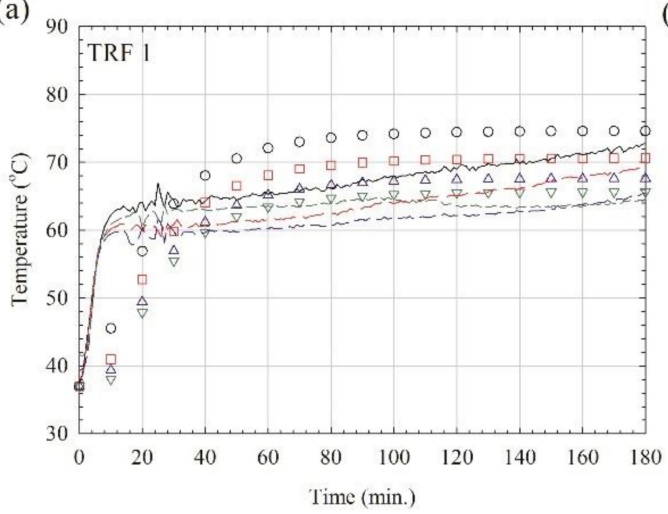

(c)

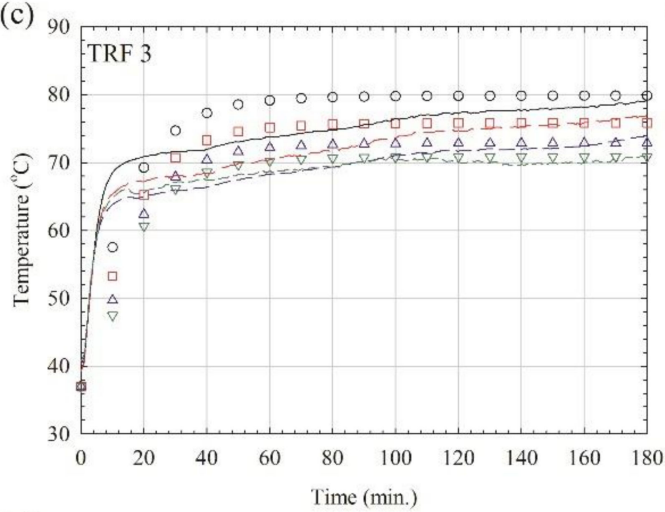

(e)

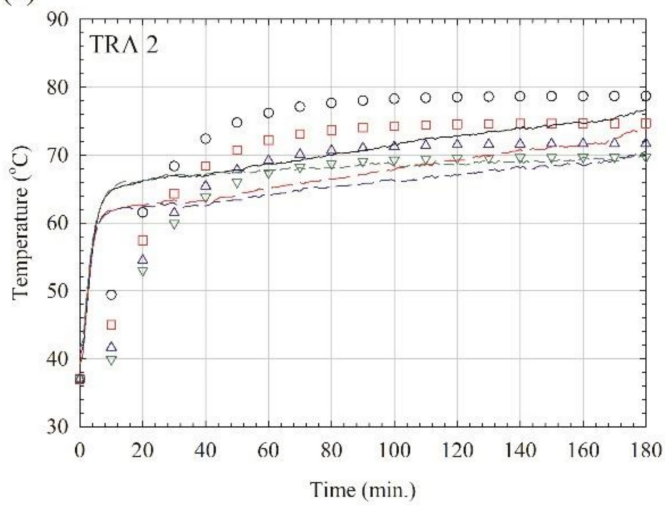

(b)

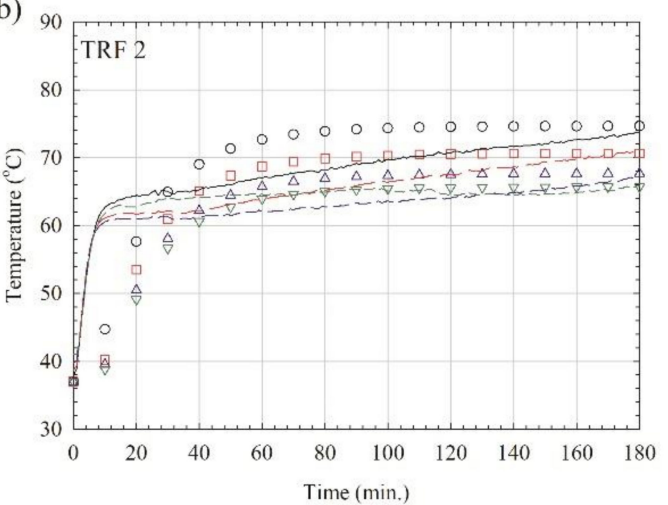

(d)

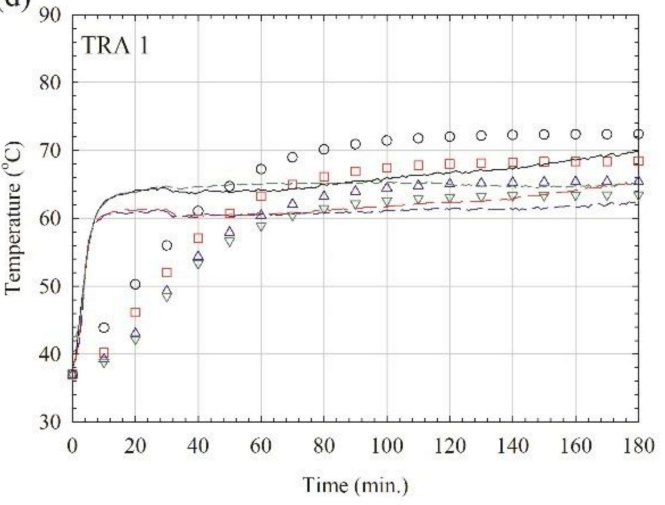

Figure 8. Variation in temperature distribution of (a) TRF1, (b) TRF2, (c) TRF3, (d) TRA1, and (e) TRA2.

In the simulation, the temperature is high in the order of height without exception. The reason is that the continuous collapse of upper solid AC into the lower space by the effect of gravity was taken into account in the simulation. From the above results, it can be mentioned that it is challenging to accurately predict the spatial temperature distribution in the reactor where $\mathrm{AC}$ sublimation occurs because it is necessary to accurately predict the collapse of the solid AC existing in the upper or surrounding area into the lower empty space.

\section{Conclusions}

In this study, a numerical model for the sublimation of AC is newly developed. To effectively simulate the sublimation of $\mathrm{AC}$ in a reactor, the calculation zones are divided into three zones with different characteristics: solid-phase zone, gas-phase zone, and sublimation zone. Depending on the sublimation critical temperature $\left(T_{t h}\right)$ and the solidphase and gas-phase mass ratio $\left(\rho_{S}\right)$ in the zone, the solid-phase zone changes to the 
sublimation zone and then to the gas-phase zone. This study also simply modeled the collapse of upper solid AC into the lower empty space, which is created by sublimation.

The simulation results were compared with the experimental results of AC sublimation in a simplified reactor. It is found that the modeling can show very credible information about the phenomena of AC sublimation, such as temperature change with time, the reactor pressure, and sublimated gas flow rate. It is also conjectured that the heat transfer in the reactor is reasonably simulated because the shape variation of solid AC in the experiment is similar to that in the simulation. However, the accurate prediction of spatial temperature distribution is challenging because it is related to the accurate prediction concerning the collapse of the solid AC existing in the upper or surrounding area into the lower empty space, caused by sublimation.

Author Contributions: Model development and simulation, J.-H.N., experiment and writing-original draft, S.-H.W., writing-review and editing, H.R., conceptualization, and supervision, H.K. All authors have read and agreed to the published version of the manuscript.

Funding: This research was funded by the Korea Institute of Machinery \& Materials, Republic of Korea, under the project name of "The ultra clean machinery technologies of future electric generation or power systems against PM2.5 fine particles and greenhouse gases", grant number NK231A.

Institutional Review Board Statement: Not applicable.

Informed Consent Statement: Not applicable.

Conflicts of Interest: The authors declare no conflict of interest.

\section{References}

1. Xu, L.; Tsona, N.T.; You, B.; Zhang, Y.; Wang, S.; Yang, Z.; Xue, L.; Du, L. NOx enhances secondary organic aerosol formation from nighttime $\gamma$-terpinene ozonolysis. Atmos. Environ. 2020, 225, 117375. [CrossRef]

2. 2014 National Emissions Inventory Technical Support Document. Available online: https://www.epa.gov/sites/production/ files /2018-07/documents / nei2014v2_tsd_05jul2018.pdf (accessed on 23 June 2021).

3. Gou, X.; Wu, C.; Zhang, K.; Xu, G.; Si, M.; Wang, Y.; Wang, E.; Liu, L.; Wu, J. Low temperature performance of selective catalytic reduction of $\mathrm{NO}$ with $\mathrm{NH} 3$ under a concentrated $\mathrm{Co} 2$ atmosphere. Energies 2015, 8, 12331-12341. [CrossRef]

4. Li, L.; Lin, W.; Zhang, Y. A new dynamic injection system of urea-water solution for a vehicular select catalyst reduction system. Energies 2017, 10, 12. [CrossRef]

5. Fulks, G.; Fisher, G.B.; Rahmoeller, K.; Wu, M.C.; Herde, E. A review of solid materials as alternative ammonia sources for lean NOx reduction with SCR. SAE Int. 2009. [CrossRef]

6. Gramigni, F.; Nasello, N.D.; Selleri, T.; Nova, I.; Tronconi, E.; Dieterich, S.; Weibel, M. Unexpected low-temperature deNOx activity of AdSCR systems for cold start NOx abatement. Emiss. Control Sci. Technol. 2020, 6, 402-409. [CrossRef]

7. Choi, B.C.; Kim, Y.K.; Jhung, W.N.; Lee, C.H.; Hwang, C.Y. Experimental investigation on melting characteristics of frozen urea-water-solutions for a diesel SCR de-Nox-system. Appl. Therm. Eng. 2013, 50, 1235-1245. [CrossRef]

8. Jeong, S.; Kim, H.; Kim, H.; Kwon, O.; Park, E.; Kang, J. Optimization of the urea injection angle and direction: Maximizing the uniformity index of selective catalytic reduction system. Energies 2020, 14, 157. [CrossRef]

9. Kim, Y.; Raza, H.; Lee, S.; Kim, H. Study on the thermal decomposition rate of ammonium carbamate for a diesel NOx reducing agent-generating system. Fuel 2020, 267, 117306. [CrossRef]

10. Kim, H.; Yoon, C.; Lee, J.; Lee, H. A study on the solid ammonium SCR system for control of diesel NOx emissions. SAE Int. 2014. [CrossRef]

11. Lacin, F.; Kotrba, A.; Hayworth, G.; Sullivan, H.; Tatur, M.; Jacques, J.; Tomazic, D.; Cho, H. Solid SCR: Demonstrating an improved approach to NOx reduction via a solid reductant. SAE Int. 2011. [CrossRef]

12. Costa, M.; Oliva, A.; Perez Segarra, C.D.; Alba, R. Numerical simulation of solid-liquid phase change phenomena. Comput. Methods Appl. Mech. Eng. 1991, 91, 1123-1134. [CrossRef]

13. Huo, Y.; Rao, Z. Lattice Boltzmann simulation for solid-liquid phase change phenomenon of phase change material under constant heat flux. Int. J. Heat Mass Transf. 2015, 86, 197-206. [CrossRef]

14. Chabot, C.; Gosselin, L. Solid-liquid phase change around a tube with periodic heating and cooling: Scale analysis, numerical simulations and correlations. Int. J. Therm. Sci. 2017, 112, 345-357. [CrossRef]

15. Gong, S.; Cheng, P. A lattice Boltzmann method for simulation of liquid-vapor phase-change heat transfer. Int. J. Heat Mass Transf. 2012, 55, 4923-4927. [CrossRef]

16. Fang, W.Z.; Tang, Y.Q.; Yang, C.; Tao, W.Q. Numerical simulations of the liquid-vapor phase change dynamic processes in a flat micro heat pipe. Int. J. Heat Mass Transf. 2020, 147, 119022. [CrossRef] 
17. Kim, C.; Lee, J.; Lee, K.S. Numerical modeling of frost growth and densification on a cold plate using frost formation resistance. Int. J. Heat Mass Transf. 2017, 115, 1055-1063. [CrossRef]

18. Zhang, C.; Bu, X.; He, J.; Liu, C.; Lin, G.; Miao, J. Simulation of evaporation and sublimation process in porous plate water sublimator based on a reduced CFD model. Int. J. Heat Mass Transf. 2020, 154, 119787. [CrossRef]

19. Zadravec, M.; Casar, Z.; Hribersek, J.R.M. CFD based determination of sublimation mass flux for lyophilization inside a vial. Int J. Comput. Methods Exp. Meas. 2020, 8, 47-60. [CrossRef]

20. Ahn, C.; Lee, H.; Lee, M.; Chang, Y.; Han, K.; Rhee, C.; Kim, J.; Chun, H.; Park, J. Determination of Ammonium Salt/Ion Speciation in the CO2 Absorption Process Using Ammonia Solution: Modeling and Experimental Approaches. Energy Procedia. 2011, 4, 541-547. [CrossRef] 